\title{
Test anxiety and its effect on the speed-accuracy tradeoff function
}

\author{
PAULA GOOLKASIAN \\ University of North Carolina, Charlotte, North Carolina 28223
}

\begin{abstract}
Test-anxious and non-test-anxious students performed a letter classification task under speeded and unspeeded conditions. The speed and accuracy of the students' "same-different" judgments were analyzed to reveal effects of group, response deadline, and presence of an exam. Test-anxious students were found to respond slower than non-test-anxious students, and this group difference was not influenced by emphasis on speed or accuracy, or by the presence of an exam.
\end{abstract}

Test anxiety has been found to interfere with performance in classroom settings (Alpert \& Haber, 1960; Daniels \& Hewitt, 1978; Osterhouse, 1975; Ray, Katahn, \& Snyder, 1971), as well as performance on laboratory tasks (Deffenbacher, 1978; Holroyd, Westbrook, Wolf, \& Badhorn, 1978; Nottelmann \& Hill, 1977). Daniels and Hewitt (1978) found that students designated as highly test anxious by means of a score on a test-anxiety questionnaire performed significantly lower on a classroom examination than did students designated as low or moderately test anxious. Also, the difference between the anxiety groups appeared to be greater with more difficult items. Similarly, Alpert and Haber (1960) and Osterhouse (1975) found a negative relationship between anxiety level and measures of academic performance. Test anxiety has also been found to interfere with performance on anagram tasks. Subjects who are highly test anxious were found to be slower at solving anagrams (Holroyd et al., 1978) and, when asked to solve the anagrams in a high-stress situation, showed more interference and solved fewer anagrams than the low test-anxious subjects (Deffenbacher, 1978).

In a review of the interference effects associated with test anxiety, Wine (1971) suggested that an explanation might be found in the way test-anxious and non-testanxious students attend to task-relevant variables. Test-anxious students are more easily distracted by the pressures of the test environment and they tend to be more concerned with themselves, whereas non-testanxious students focus their attention more on the task at hand.

The purpose of this experiment was to study whether the performance decrement found in association with

The author would like to thank Marilyn Turner for her assistance in testing the subjects and in analyzing the data. Requests for reprints should be sent to Paula Goolkasian, Department of Psychology, University of North Carolina, Charlotte, North Carolina 28223. This study was partially funded by a faculty grant from the University of North Carolina at Charlotte Foundation. the presence of test anxiety could be attributed to basic differences in the way test-anxious and non-test-anxious students respond. Students designated as test anxious or non-test anxious by a score on the Achievement Anxiety Test (AAT) (Alpert \& Haber, 1960) were asked to participate in a letter classification task in which they made "same-different" judgments. "Same" responses indicated that a letter pair consisted of both vowels or both consonants, and "different" responses indicated that they were mixed (Posner \& Mitchell, 1967). Also, a responsedeadline technique was used to assess the students' responses at various positions along the speed-accuracy tradeoff function. Speeded and unspeeded conditions were established through instructions to respond within $1.0, .7$, or $.4 \mathrm{sec}$ (Pachella \& Fisher, 1969). Previous experiments found that test anxiety impaired performance on classroom exams, as well as on laboratory tasks. This experiment tested whether the performance impairments attributed to test-anxious students could be explained more specifically by an effect on the speed and/or accuracy of the students' responses. And a related question addressed by this experiment was to what degree did task instructions emphasizing speed and/or accuracy influence performance? Support for Wine's (1971) hypothesis would be found if the response times or accuracy measures were found to be affected by testanxiety groups. If test-anxious students are more concerned about irrelevant variables when distracted by the pressures of the test environment, then they should show performance decrements under all three instruction conditions when compared with the non-testanxious students.

Another variable that was of interest in this experiment was the presence of a classroom exam. The students were asked to participate in this experiment twice: within $1 \mathrm{~h}$ of a course exam and within $1 \mathrm{~h}$ of a nonexam class in the same course. This manipulation provided additional information regarding the effects of test anxiety as a within-subjects variable. Effects of test anxiety associated with the presence of an exam would be revealed by testing for an effect of this variable and 
for any interaction of this variable with test-anxious groups or deadline conditions.

\section{METHOD}

\section{Subjects}

Sixteen male and female students from the University of North Carolina at Charlotte were selected from volunteers who took the AAT (Alpert \& Haber, 1960) on the 1st day of class. The AAT is a 19-item questionnaire consisting of a facilitating anxiety scale, which measures the degree to which test anxiety improves student performance, and a debilitating anxiety scale, which measures the interference effect of test anxiety. The test-retest reliability of the AAT was high (.75), and performance on the two scales was found to be negatively correlated (rs range from -.37 to -.48 ) (Alpert \& Haber, 1960). The eight subjects in the test-anxiety group were selected from those who scored at least 1 standard deviation above the mean on the debilitating scale and below the mean on the facilitating scale. (Scores ranged from 34 to 40 on the debilitating scale and from 16 to 24 on the facilitating scale.) Non-test-anxious subjects were selected from those who obtained scores that were above the mean on the facilitating scale and below the mean on the debilitating scale (scores ranged from 26 to 36 on the facilitating scale and from 17 to 27 on the debilitating scale). There were three male and five male students in each of the groups.

\section{Materials and Apparatus}

The stimuli in the letter classification task were pairs of letters. The letters were typed on acetate paper in black uppercase characters with an IBM Selectric and placed into slide mounts. The stimulus pair appeared in the center of the screen, and it covered an area of 2 deg of visual angle. One hundred and fifty pairs of letters were used. Half of these were "same" pairs, which were composed of two different letters, both of which were either vowels or consonants. The "different" pairs were made up of a vowel and a consonant. The pairs were randomly selected from all possible combinations of the 26 letters of the alphabet, with the restriction that there be an equal number of vowels and consonants.

The stimuli were rear-projected onto a screen by means of a Kodak Carousel slide projector with a built-in shutter. BRSLVE electromechanical control panels were used to control the presentation of the slides. Reaction times were measured by a Berle digital timer/counter from the time of onset of the stimulus pair and were recorded on a four-column printer.

\section{Procedure}

Subjects participated individually in three sessions. The first session lasted $1 \mathrm{~h}$ and was conducted to give the subject an opportunity to practice with the letter classification task and with the various time constraints. The subjects were asked on each trial to determine whether the members of the letter pair were the same or different within one of three deadlines: 1.0 , .7 , and $.4 \mathrm{sec}$. The subjects were required to respond faster than the deadline and, within the time constraint, to be as accurate as possible. They monitored a clock timer to receive immediate feedback on their response latencies, and they received verbal warnings from the experimenter when their responses were longer than the deadlines. After participating in a block of unspeeded trials, the subjects were asked to respond in successive blocks of 100 trials. The presentation order of the deadline conditions for the practice session was $1.0, .7$, and $.4 \mathrm{sec}$.

The second and third sessions constituted the experimental sessions. They were $30 \mathrm{~min}$ in length and were held within 1 week of the practice sessions. They were scheduled such that one session would occur within $1 \mathrm{~h}$ of a course exam (exam) and the other would occur within $1 \mathrm{~h}$ of a nonexam class (control) in the same course. Half of the subjects participated in the control session
2 days earlier than the exam session, and the remaining students did the reverse.

The exam and control sessions were included to test for effects of test anxiety that might accompany the presence or absence of a course exam. To provide some assurance of the internal validity of the manipulation (i.e., that students were more anxious $1 \mathrm{~h}$ before their course exam than $1 \mathrm{~h}$ before a nonexam class), a study was conducted in which Speilberger's State Anxiety Inventory was administered to two classes of students. Each class filled out the inventory twice, once within $1 \mathrm{~h}$ of an exam and another time within $1 \mathrm{~h}$ of a nonexam class. The order of the exam and control sessions was counterbalanced across classes. Mean scores from the exam session indicated significantly more anxiety than the scores from the control session $[t(16)=4.70, p<.01]$. (Means for the exam and control sessions are, respectively, 47 and 34.) These results were interpreted to support the assumption that students participating in an experiment $1 \mathrm{~h}$ before an exam are more anxious than students who participate in an experiment $1 \mathrm{~h}$ before a nonexam class.

During the experimental sessions, the subjects participated in 20 practice trials and in 50 trials under each of the three deadline conditions. Presentation order of the three deadlines were counterbalanced so that half of the subjects participated in blocks of trials in the order $1.0, .7$, and $.4 \mathrm{sec}$ and the remaining half participated in the reverse order, $.4, .7$, and $1.0 \mathrm{sec}$. The 150 letter pairs were randomly ordered and separated into three blocks. The item blocks were assigned to deadline conditions in counterbalanced order across subjects.

To respond, the subjects pressed either a left- or righthanded microswitch that corresponded to "same" or "different." Designation of left- or right-handed switches as "same" or "different" was counterbalanced across subjects.

\section{Design and Data Analysis}

A 2 by 2 by 3 by 2 design was used. Two groups of subjects (test anxious and non-test anxious) were tested in two sessions (exam and control) under three deadlines $(1.0, .7, .4 \mathrm{sec})$ and two response types (same and different). Mean reaction times were computed by summing the correct responses within each of the 24 experimental conditions. Also, the proportion of correct responses was recorded and transformed into a $\mathrm{d}^{\prime}$ score (Hacker \& Raticliff, 1979). A multivariate analysis of variance (MANOVA) with follow-up univariate analysis of variance (ANOVA) were conducted on the mean reaction times and the $\mathrm{d}^{\prime}$ scores to test for main effects and interaction effects among the four variables of interest. The test statistic for the MANOVA was the Hotelling-Lawley Trace. Median reaction times were also computed. However, since they were found to correlate highly $(r=.97)$ with the mean reaction time, they were not analyzed.

\section{RESULTS}

Performance measures obtained under each of the experimental conditions are presented in Table 1. The most interesting effect revealed by the MANOVA was a significant effect of group $[\mathrm{F}(2,13)=4.10, \mathrm{p}<.04]$. The follow-up univariate test showed that this effect was due to group differences in response latency $[F(1,14)=7.44, p<.01]$, rather than to the proportion of correct responses $(F<1)$. Students who were test anxious responded with longer reaction times than the non-test-anxious students. Figure 1 presents the group differences in response speed as a function of the deadline conditions. 
Table 1

Mean Correct Response Latencies and d' Scores

\begin{tabular}{|c|c|c|c|c|c|c|c|c|c|c|c|c|}
\hline \multirow{4}{*}{$\begin{array}{c}\text { Response } \\
\text { Type }\end{array}$} & \multicolumn{12}{|c|}{ Deadline } \\
\hline & \multicolumn{6}{|c|}{ Exam } & \multicolumn{6}{|c|}{ Control } \\
\hline & \multicolumn{2}{|c|}{1.0} & \multicolumn{2}{|c|}{.7} & \multicolumn{2}{|c|}{.4} & \multicolumn{2}{|c|}{1.0} & \multicolumn{2}{|c|}{.7} & \multicolumn{2}{|c|}{.4} \\
\hline & $\mathrm{RT}$ & $\mathrm{d}^{\prime}$ & $\mathrm{RT}$ & $d^{\prime}$ & $\mathrm{RT}$ & $\mathrm{d}^{\prime}$ & RT & $\mathrm{d}^{\prime}$ & RT & $\mathrm{d}^{\prime}$ & $\mathrm{RT}$ & $\mathrm{d}^{\prime}$ \\
\hline & \multicolumn{12}{|c|}{ Test-Anxious Group } \\
\hline \multirow{2}{*}{ Different } & .717 & 1.88 & .613 & 1.23 & $\begin{array}{r}.396 \\
394\end{array}$ & $\begin{array}{r}.33 \\
16\end{array}$ & $\begin{array}{l}.723 \\
743\end{array}$ & $\begin{array}{l}1.96 \\
1.76\end{array}$ & $\begin{array}{l}.624 \\
625\end{array}$ & $\begin{array}{r}1.29 \\
87\end{array}$ & .412 & .31 \\
\hline & \multicolumn{12}{|c|}{ Non-Test-Anxious Group } \\
\hline $\begin{array}{l}\text { Same } \\
\text { Different }\end{array}$ & $\begin{array}{l}.694 \\
.707\end{array}$ & $\begin{array}{l}1.88 \\
1.75\end{array}$ & $\begin{array}{l}.568 \\
.578\end{array}$ & $\begin{array}{r}.96 \\
1.20\end{array}$ & $\begin{array}{l}.326 \\
.324\end{array}$ & $\begin{array}{r}.35 \\
-.18\end{array}$ & $\begin{array}{l}.694 \\
.735\end{array}$ & $\begin{array}{l}1.79 \\
1.59\end{array}$ & $\begin{array}{l}.575 \\
.589\end{array}$ & $\begin{array}{l}.99 \\
.68\end{array}$ & $\begin{array}{l}.320 \\
.342\end{array}$ & $\begin{array}{r}.33 \\
-.05\end{array}$ \\
\hline
\end{tabular}

As expected, there was a main effect of deadline $[F(4,52)=105.81, p<.01]$, and this effect was found to be significant in the analysis on both the latency scores $[\mathrm{F}(2,28)=147.11, \mathrm{p}<.01]$ and the $\mathrm{d}^{\prime}$ scores $[F(2,28)=67.08, p<.01]$. The presence of a deadline effect indicated that the subjects were following the instructions and trading speed for accuracy. Although in Figure 1 it appears as though group differences were greatest when speed was emphasized, the analysis showed that group differences did not interact with deadline conditions $(F<1)$. Test-anxious students responded slower than non-test-anxious students regardless of emphasis on speed or accuracy.

Participating in the experiment within $1 \mathrm{~h}$ of a course exam did not result in any significant changes in either performance speed or accuracy $(F<1)$, nor was this variable found to interact with any other variable $(F s<1)$. Response type was also found to be nonsignificant $[F(2,10)=1.23, p<.32]$, together with its interaction with all other variables $(\mathrm{Fs}<1)$.

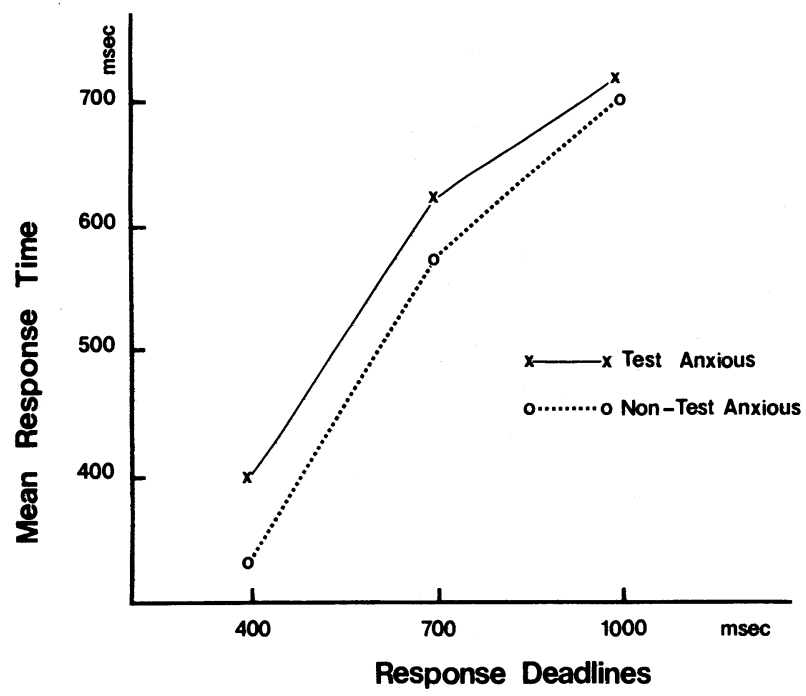

Figure 1. Group differences in response latencies under each of the deadline conditions.
Error latencies were computed, and in general, the data show the same pattern of results as the correct latencies. Reaction times were longer for the test-anxious group than for the non-test-anxious students, and the group differences appeared to narrow with increasing emphasis on accuracy. When compared with the correct latencies, the error reaction times were, in general, slightly faster, with the exception of the condition in which accuracy was emphasized. Within this deadline condition, the error latencies were the same as the correct latencies.

Item variances were also analyzed to determine whether there were any effects as a function of the four variables of interest. There were no group differences $[F(1,44)=2.68, p<.12]$ or effects due to the presence or absence of an exam $(\mathrm{F}<1)$, but item variances were found to be affected by the deadline conditions $[F(2,28)=5.72, p<.01]$. With decreased emphasis on speed, response latencies to items within a condition became more variable.

\section{DISCUSSION}

The findings of this experiment were that students who were designated as test anxious through their performance on a testanxiety questionnaire reacted with longer latencies than nontest-anxious students when asked to make same-different judgments. The group differences in response latencies occurred consistently across several speeded and unspeeded conditions. Also, test-anxious subjects were not found to differ from nontest-anxious subjects in the accuracy of their performance, only in the speed. These results suggest that test-anxious students are capable of performing just as accurately as non-test-anxious students, but they need more time to do so.

These findings are consistent with some of the previous studies that used performance on an anagram task as a measure of the interfering effects of test anxiety (Deffenbacher, 1978; Holroyd et al., 1978). However, from these results it is evident that the difficulty experienced by the test anxious group in solving the anagrams could have been a function of the slower response rate of this group rather than a result of a lowered ability at performing the task when compared with students who were non-test anxious.

A possible explanation for the latency difference that was obtained between the groups could be found in the cognitive attentional hypothesis of Wine (1971). According to this theory, 
test-anxious students perform at a lower criterion because of a lack of attention to task-relevant cues. In a highly evaluative testing environment, test-anxious students are more vulnerable to distractions than are non-test-anxious students. Since all of the deadline conditions used in this study placed students under pressure to perform within either speed or accuracy constraints, then, perhaps the test-anxious students were distracted by the test environment to a much greater degree than the non-testanxious students. They could have been easily distracted by the clock timer, which was constantly in their view to provide immediate feedback regarding their response speeds, or they could have spent time and attention worrying during the intertrial interval or have been preoccupied with how well they were doing. The presence of any one of these conditions would have been enough to lengthen the response latencies.

The presence of an exam within $1 \mathrm{~h}$ of the experimental participation did not affect performance on the letter classification task. A possible reason for this result is that the effects associated with the presence of an exam are so specific that they can be produced only within the exam setting itself and cannot be generalized to other tasks outside the actual classroom. Even though a pilot study demonstrated that subjects were more anxious $1 \mathrm{~h}$ before an exam than they were $1 \mathrm{~h}$ before a routine nonexam class, this increase in anxiety within the individual subject did not appear to affect performance on a laboratory task involving letter classifications.

In summary, then, the findings of this experiment suggest that the performance effects typically obtained when testanxious students are compared with non-test-anxious students in a classroom or in a laboratory setting could be due to a basic difference in the rate at which these groups respond to tasks. When compared with non-test-anxious students, test-anxious students perform at the same level of accuracy, but their response rate is much slower.

\section{REFERENCES}

Alpert, R., \& Haber, R. Anxiety in academic achievement situation. Journal of Abnormal and Social Psychology, 1960, 61, 207-215.

Daniels, B., \& Hewitt, J. Anxiety and classroom examination performance. Journal of Clinical Psychology, 1978, 34, 340-345.

DeFFenBACher, J. L. Worry, emotionality and task-generated interference in test anxiety: An empirical test of attentional theory. Journal of Educational Psychology, 1978, 70, 248-254.

Hacker, M. J., \& RAtcliff, R. A revised table of d' for M-alternative forced choice. Perception \& Psychophysics, 1979, 26, 168-176.

Holroyd, K. A., Westbrook, T., Wolf, M., \& Badhorn, E. Performance, cognition, and physiological responding in test anxiety. Journal of Abnormal Psychology, 1978, 87, 442-451.

Nottelmann, E. D., \& Hill, K. T. Test anxiety and off-task behavior in evaluation situations. Child Development, 1977, 48, 225-231.

Osterhouse, R. Classroom anxiety and the examination performance of test-anxious students. Journal of Educational Research, 1975, 68, 247-250.

Pachella, R. G., \& Fisher, D. F. Effect of stimulus degradation and similarity on the trade-off between speed and accuracy in absolute judgments. Journal of Experimental Psychology, $1969,81,7-9$.

Posner, M. I., \& Mitchell, R. F. Chronometric analysis of classification. Psychological Review, 1967, 74, 392-409.

Ray, W. J., Katahn, M., \& Snyder, C. R. Effects of test anxiety on acquisition, retention, and generalization of a complex verbal task in a classroom situation. Journal of Personality and Social Psychology, 1971, 20, 147-154.

WINE, J. Test anxiety and direction of attention. Psychological Bulletin, 1971, 76, 92-104.

(Received for publication December 12, 1981.) 